Relations industrielles

Industrial Relations

\title{
Table de l'année 1947-1948
}

Volume 3, numéro 10, juin 1948

URI : https://id.erudit.org/iderudit/1023644ar

DOI : https://doi.org/10.7202/1023644ar

Aller au sommaire du numéro

Éditeur(s)

Département des relations industrielles de l’Université Laval

ISSN

0034-379X (imprimé)

1703-8138 (numérique)

Découvrir la revue

Citer ce document

(1948). Table de l'année 1947-1948. Relations industrielles / Industrial Relations, 3(10), 159-159. https://doi.org/10.7202/1023644ar

Tous droits réservés (C Département des relations industrielles de l’Université Laval, 1948
Ce document est protégé par la loi sur le droit d'auteur. L'utilisation des services d'Érudit (y compris la reproduction) est assujettie à sa politique d'utilisation que vous pouvez consulter en ligne.

https://apropos.erudit.org/fr/usagers/politique-dutilisation/ 


\section{TABLE DE L'ANNÉE 1947-1948}

Accidents du travail, La compensation des - Frédéric $T$. Hecker, No 6, février, pp. 91-95.

Apprenticeship Commission in the building industry, An (A Realization) - J.L.E. Price, No. 10, June, pp. 153-155.

Association et corporation - No 3, novembre, pp. 44-46.

Bureau de placement, Un - Jean Gagné, No 3, novembre, pp. 43-44.

Cartels intersyndicaux, Unité syndicale et - Jean-Pierre Després, No 7, mars, pp. 106-108.

Cas pratique - Donat Quimper, No 2, octobre, p. 30.

Catholicisme social face aux grands courants contemporains - Lettre de Sa Sainteté Pie XII à M. Charles Flory, No 1, septembre, pp. 10-12.

Collective Labour Agreements, The Renewal Clause of Georges-Michel Giroux, No. 8, April, pp. 124-127.

Comité paritaire, Rôles respectifs du secrétaire et de l'inspecteur du - J.-Médard Ouellet, No 2, octobre, pp. 28-30.

Comités d'entreprises, Les - Raymond Gérin, No 8, avril, pp. 117-119.

Commission d'apprentissage des métiers du bâtiment, Une (Une réalisation) - J.L.E. Price, No 10, juin, pp. 151-153.

Communist Manifesto, The - Egbert Munzer, No. 7, March, pp. 103-106.

Congés annuels payés dans le Québec, Les - Charles Bélanger, No 10, juin, pp. 148-151.

Congrès, Notre troisième - La Direction, No 6, février, pp. 81, 95. Réflexions sur le troisième congrès La Direction, No 8, avril, p. 113. Echos du troisième congrès: Audace et franchise - Gaston Cholette, No 10, juin, p. 156. Building the Christian Social Order - Henry Sommerville, No. 10, June, p. 156.

Convention, Our third annual - The Editors, No. 6, February, p. 96. Some Reflexions on the Third Convention - The Editors, No. 8, April, p. 128.

Conventions collectives, Clause de renouvellement dans les - Georges-Michel Giroux, No 8, avril, pp. 119-122.

Coopération des patrons et des apprentis - J.L.E. Price, No 9, mai, pp. 137-139.

Co-operation in Apprenticeship Training, Labour management - J.L.E. Price, No. 9, May, pp. 139-141.

Corporation, Association et - No 3, novembre, pp. 44-46.

Décret, Rôles respectifs du secrétaire et de l'inspecteur du comité paritaire - J.-Médard Ouellet, No 2, octobre, pp. 28-30.

Démocratie ouvrière en oeuvre - Jean Gagné, No 2, octobre, pp. 22-26.

«Différend 》, Le sens des termes «salarié 》 et - MarieLouis Beaulieu, No 5, janvier, pp. 74-78.

Distributisme social et stabilité ouvrière - Gonzalve Poulin, o.f.m., No 1, septembre, pp. 8-10.

Editorial: Une troisième année - La Direction, No 1, septembre, p. 1. Rétrospective 1947 - La Direction, No 4, décembre, pp. 49-51.

Editorial: Our Third Year - The Editors, No. 1, September, p. 16. Retrospective 1947 - The Editors, No. 4, December, pp. 63-64.

Effectif syndical - No 3, novembre, pp. 46-47.

Enterprise, The Structure of - Marcel Clément, No. 6, February, pp. 87-91.

Enterprise, Property and - Paul-Emile Bolté, No. 3, November, pp. 40-41.

Entreprise, Propriété et - Paul-Emile Bolté, p.s.s., No 3, novembre, pp. 34-40.

Entreprise, La structure de l' - Marcel Clément, No 6, février, pp. 82-86.

Ethics in Labour Relations - Gaston Cholette, No. 2 , October, pp. 26-28.

Formation professionnelle, La - Gabriel Rousseau, No 8. avril, pp. 116-117.

Gazette du travail, La - G.D., No 10, juin, p. 158.

Grève politique ou grève économique - La Direction, No 2. octobre, p. 17.

Grèves, Réflexions sur les - Omer Genest, ptre, No 4, décembre, pp. 51-55.

Hygiène industrielle, Service d' - Gérard Dion, No 3, novembre, pp. 41-43.

Loi Taft-Hartley, La - Gérard Tremblay, No 1, septembre, pp. 2-5.
Manifeste communiste, Le - Egbert Munzer, No 7, mars, pp. 99-103.

Manuels techniques français - No 4, décembre, p. 62.

Organisation représentative, Qu'est-ce qu'une?' - JeanPierre Després, No 2, octobre, pp. 20-22.

Organisation du travail - No 9, mai, pp. 141-142.

Participation ( $\mathrm{La}$ ) des travailleurs aux bénéfices est-elle un cadeau? - Gérard Dion, No 9, mai, pp. 132-137

Paternité, patronat, paternalisme - Marcel Clément, No 5, Janvier, pp. 65-68.

Paternity, Patronate, Paternalism - Marcel Clément, No. 5, January, p. 80.

Personnel, Le remplacement du - Germain Giroux, No 5, janvier, pp. 69-71.

Personnel Management - Germain Giroux, No. 5, January, pp. 71-73.

Placement, Un bureau de - Jean Gagné, No 3, novembre, pp. 43-44.

Prix, Augmentation de salaire et hausse de - Gérard Dion, No 1, septembre, pp. 5-7.

Profession, Semaine sociale de France et - No 3, novembre, p. 47.

Programme-souvenir, programme d'avenir - No 1, septembre, p. 15 .

Propriété, A propos de - André Roy, No 5, janvier, pp. 68-69.

Propriété et entreprise - Paul-Emile Bolté, p.s.s., No 3 , novembre, pp. 34-40.

Property and Enterprise - Paul-Emile Bolté, p.s.s., No. 3, November, pp. 40-41.

Publications reçues au Département des relations industrielles de Laval, Liste des, No 7, mars, pp. 108-110.

Reforms, Structural - Gérard Dion, No. 3, November, p. 48.

Réformes de structure - Gérard Dion, No 3, novembre, p. 33.

Réformes de structure, L'esprit des: Paternité, patronat, paternalisme - Marcel Clément, No 5, janvier, pp. 65-68. Les problèmes qui se posent - Marcel Clément, No 7, mars, pp. 97-99. La structure de l'entreprise - Marcel Clément, No 6, février, pp. 82-86. Les solutions proposées - Marcel Clément, No 8, avril, pp. 114-116. No 9, mai, pp. 129-132. No 10, juin, pp. 145-148. Propriété et entreprise - PaulEmile Bolté, No 3, novembre, pp. 34-40. Réformes de structure - Gérard Dion, No 3, novembre, p. 33. La participation des travailleurs aux bénéfices est-elle un cadeau? - Gérard Dion, No 9, mai, pp. 132-137.

Reforms, The Spirit of Structural: Paternity, Patronate, Paternalish - Marcel Clément, No. 5, January, p. 80. The Structure of Enterprise - Marcel Clément, No. 6, February, pp. 87-91. The Problems which Present Themselves - Marcel Clément, No. 7, March, pp. 110-11-112. Proposed Solutions - Marcel Clément, No. 8, April, pp. 122-124. No. 9, May, pp. 142-144. No. 10, June, pp. 157-158-160. Property and Enterprise - Paul-Emile Bolté, p.s.s., No. 3, November, pp. 4041. Structural Reforms - Gérard Dion, No. 3, November, p. 48.

Relations du travail, La morale dans les - Gaston Cholette, No 3, octobre, pp. 19-20.

Relations Plan, Our industrital - W.J. Whitehead, No. 4, November, pp. 59, 60, 61, 63.

Salaire, Augmentation de... et hausse de prix - Gérard Dion, No 1, septembre, pp. 5-7.

«Salarié 》 et «Différend », Le sens des termes - MarieLouis Beaulieu, c.r., No 5, janvier, pp. 74-78.

Sécurité syndicale et morale - Gaston Cholette, no 10 , juin, p. 158 .

Solution courageuse, Une - W.J. Whitehead, No 4, décembre, pp. 55-58.

Stabilité ouvrière et distributisme social - Gonzalve Poulin, o.f.m., No 1, septembre, pp. 8-10.

Strike, Political or Economic - The Editors, No. 3, October, p. 32 .

Travail, Humanisation du - J.-T. Delos, No 1, septembre, p. 7 .

Unité syndicale et cartels intersyndicaux - Jean-Pierre Després, No 7, mars, pp. 106-108. 